\title{
Uterine Corpus Epithelioid Leiomyosarcoma
}

National Cancer Institute

\section{Source}

National Cancer Institute. Uterine Corpus Epithelioid Leiomyosarcoma. NCI Thesaurus.

Code C40174.

A morphologic variant of leiomyosarcoma arising from the uterine corpus. It is

characterized by the presence of epithelioid round cells with eosinophilic to clear cytoplasm. 